http://www.asce.org/issues and advocacy/

This is a pre-copyedited, author-produced PDF of an article accepted for publication in JOURNAL OF ENGINEERING MECHANICS following peer review. The version of record ANALYTICAL MODEL FOR RESIDUAL BOND STRENGTH OF CORRODED REINFORCEMENT IN CONCRETE STRUCTURES is available online at: $\underline{\text { http://dx.doi.org/10.1061/(ASCE)EM.1943-7889.0000997 }}$

\title{
Analytical Model for Residual Bond Strength of Corroded Reinforcement
}

\section{in Concrete Structures}

\author{
Hua-Peng Chen ${ }^{1}$ and Jaya Nepal ${ }^{2}$
}

\begin{abstract}
Bond strength deterioration in corrosion damaged reinforced concrete structures significantly affects serviceability and load carrying capacity in their remaining service life. This paper presents a new analytical model for predicting the cracking development in the surrounding concrete and the residual bond strength of rebar in concrete structures due to reinforcement corrosion. The proposed analytical method adopts the thick-walled cylinder model for the cover concrete and considers the realistic properties of the corrosion-induced cracked concrete such as anisotropic behaviour, residual tensile strength and reduced tensile stiffness. As corrosion progresses, three phases for bond strength evolution associated with concrete cracking development are defined and the corresponding corrosion levels in each phase are determined. By using the constructed new governing equation, the crack width growth in the concrete cover and the radial bursting pressure at the bond interface are evaluated. The ultimate bond strength is then estimated from the contributions of adhesion,
\end{abstract}

\footnotetext{
${ }^{1}$ Corresponding Author. Professor of Civil Engineering, Department of Engineering Science, University of Greenwich, Chatham Maritime, Kent ME4 4TB, U. K. E-mail: h.chen@greenwich.ac.uk

${ }^{2} \mathrm{PhD}$ student, Department of Engineering Science, University of Greenwich, Chatham Maritime, Kent ME4 4TB, U. K. E-mail: j.nepal@greenwich.ac.uk
} 
confinement and corrosion pressure as a function of corrosion level. Finally, the effectiveness of the proposed analytical model is demonstrated by comparing the predicted results with experimental data available, and the results show that the proposed model is useful for predicting the bond strength evolution of the corroded rebar in concrete structures.

CE Database subject headings: Corrosion; Concrete; Cracking; Bonding Strength.

\section{Introduction}

In reinforced concrete (RC) structures, bond strength is considered as the interaction force which holds the composite actions between reinforcement and the surrounding concrete. As described in ACI (2003), the bond strength of deformed bars in RC structures depends on three factors, i.e. chemical adhesion between rebar and concrete, frictional force at the bond interface and mechanical anchorage of the ribs against the concrete surface. Meanwhile, research showed that corrosion of steel reinforcement may seriously affect the serviceability and ultimate bearing capacity of RC structures exposed to aggressive environments (Chen and Alani 2013; Stewart and Rosowsky1998; Zhang et al. 2010). Reinforcement corrosion consumes original steel rebar and generates expansive layer at the bond interface, leading to radial splitting cracks in the concrete. Consequently, corrosion of steel rebar can affect all factors contributing to the bond strength by reducing the size of rebar, decreasing the stiffness of the surrounding concrete, creating cracks in the concrete and changing mechanical properties of the reinforcement and concrete. In order to safely resist loading acting on the RC structures, efficient and reliable force transfer between the reinforcement and concrete is essential (FIB 2000). Hence, the evaluation of bond strength degradation is necessary to correctly predict the residual strength and remaining service life of the corroded RC structures. 
Many experimental investigations have been carried out during last two decades to study the influence of reinforcement corrosion on the bond behaviour of corroded RC structures (Fang et al. 2004; Law et al. 2011; Rodriguez et al. 1994). Most of these experimental studies were undertaken by using concentric pull-out tests on a single reinforcement bar embedded in concrete specimens, where the rebar was corroded often by using accelerated corrosion techniques. These experimental investigations show that bond strength increases at the early stage of corrosion (e.g. usually less than $1 \%$ of mass loss of the rebar), but significantly decreases when cracking occurs on the concrete cover surface and then gradually decays to zero. On the basis of these experimental results, empirical models for the relationship of the bond strength of corroded reinforcement with corrosion level have been proposed, such as in the studies by Auyeung et al. (2000), Bhargava et al. (2008), Lee et al. (2002) and Stanish et al. (1999). The applicability of these empirical models to real RC structures in operation environments may be limited, since they are mainly evaluated from specific concrete specimens and test procedures in the experiments. On the other hand, numerical investigations on the influence of reinforcement corrosion on bond strength have been conducted by using powerful finite element methods, giving conclusions similar to those from experimental investigations (Lundgren 2002; Amleh and Gosh 2006). In addition, attempts have been made to develop analytical models for predicting bond strength degradation due to reinforcement corrosion. Coronelli (2002) proposed an analytical model for estimating the bond strength of corroded reinforcement in concrete. Later, Wang and Liu ( 2004) improved the analytical model by using the corrosion pressure estimated from the thick-walled cylinder model with consideration of the tension softening for the cracked concrete. Similar problems dealing with hoop stress, radial stress and interfacial stress for fibre reinforced ceramic composites have been studied in the work by Budiansky and Hutchinson (1986) and Ho and Suo (1992). Recently, Bhargava et al. (2007) utilised similar approach and proposed an analytical model 
that includes the adhesion force at the bond interface. However, most of existing analytical models ignore the anisotropic behaviour of the cracked concrete affected by reinforcement corrosion. These models may be unable to correctly predict the crack width growth of the cover concrete and the radial pressure evolution at the bond interface as corrosion progresses. Therefore, there is a need to develop a new analytical model that can predict the crack growth in the surrounding concrete and the residual bond strength of the corroded RC structures.

This paper presents a new analytical model for predicting bond strength evolution for RC structures affected by reinforcement corrosion. The thick-walled cylinder model subject to increasing displacement generated by the expansive corrosion products at the bond interface is adopted for constructing new governing equations. As corrosion progresses, the cracked concrete is considered as an anisotropic material, where the residual tensile strength is evaluated from the realistic bilinear tension softening curve associated with concrete crack width. Three phases for bond strength evolution associated with concrete crack development are defined, i.e. crack initiation at the bond interface, crack propagation through the concrete cover and completely cracked over the cover. From the proposed analytical model, the crack width in the concrete cover and the radial corrosion pressure at the bond interface are determined in each phase. The ultimate bond strength is then estimated by considering the contributions from adhesion, confinement and corrosion pressure related to corrosion level. Finally, the proposed analytical model is verified by comparing the predicted results with experimental data available from various sources.

\section{Corrosion-induced concrete cracking model}

Reinforcement corrosion consumes original steel rebar, accumulates rust products and creates expansive layer at the bond interface. As corrosion progresses, the expansive displacement at 
the interface causes tensile stress in the hoop direction over the surrounding concrete cover, leading to radial splitting cracks in the concrete.

\section{Reinforcement corrosion}

For reinforcement corrosion in RC structures, the attack penetration $x$ (pitting attack or homogeneous corrosion) is utilised to represent the decrease of rebar diameter from initial dimension $\phi_{0}$ to residual dimension $\phi_{r}$, defined in Vidal et al. (2004) as

$$
\phi_{r}=\phi_{0}-\alpha x
$$

where $\alpha$ is attack penetration factor, indicating homogeneous corrosion when $\alpha=2$ and localised corrosion at the earlier stage when $4<\alpha<8$. The associated corrosion level $x_{p}$ is defined as the ratio of the mass loss of corroded rebar $\Delta m_{s}$ to the original rebar mass $m_{o}$ as

$$
x_{p}=\frac{\Delta m_{s}}{m_{o}}=\frac{\Delta A_{s}}{A_{0}}
$$

where $\Delta A_{s}$ is the cross-sectional area associated with the mass loss of the corroded rebar and

$A_{o}$ is the cross-sectional area of original rebar. The corrosion level $x_{p}$ can be written as a function of attack penetration $x$ or residual diameter $\phi_{r}$, namely

$$
x_{p}=2 \alpha \frac{x}{\phi_{0}}-\alpha^{2} \frac{x^{2}}{\phi_{0}^{2}}=1-\frac{\phi_{r}^{2}}{\phi_{0}^{2}}
$$

The corroded steel rebar may expand and increase the volume at the bond interface between two and four times its original volume, depending on the types of corrosion products (Liu and Weyers 1998). The volume expansion factor $\xi_{r}=A_{r} / \Delta A_{s}$ is then introduced and defined as 
the ratio of the volume of corrosion products per unit length $A_{r}$ to the loss of steel crosssectional area $\Delta A_{s}$. From Eq. (2), the volume of corrosion products per unit length $A_{r}$ is related to the corrosion level $x_{p}$, expressed as

$$
A_{r}=\xi_{r} \Delta A_{s}=\frac{\pi}{4} \xi_{r} \phi_{0}^{2} x_{p}
$$

In practice, corrosion rate could be measured on site by various methods such as by the determination of the polarization resistance, and the mass of rust products $(\mathrm{kg} / \mathrm{m})$ per unit length $M_{r}(t)$ over the duration of corrosion $t$ (year) can be estimated in Pantazopoulou and Papoulia (2001) as

$$
M_{r}(t)=\rho_{r} A_{r}(t)=\sqrt{m_{c} \pi \phi_{0} i_{c o r r} t}
$$

where $\rho_{r}$ is density of corrosion rust with an approximate value of $\rho_{r}=3600 \mathrm{~kg} / \mathrm{m}^{3} ; m_{c}$ is an empirical coefficient taken as $m_{c}=2.1 \times 10^{-2} ; i_{\text {corr }}$ represents the mean annual corrosion current per unit length at the surface area of the rebar $\left(A / \mathrm{m}^{2}\right)$. By using Eqs. (4) and (5), the corrosion level $x_{p}$ over time is estimated from the measured corrosion rate $i_{c o r r}$.

To accommodate the increase in volume per unit length $\Delta V=A_{r}-\Delta A_{s}=\left(\xi_{r}-1\right) \Delta A_{s}$, the bond interface is assumed to displace by a quantity given as

$$
\bar{u}_{b}\left(x_{p}\right)=\frac{\Delta V}{\pi \phi_{0}}=\frac{1}{4}\left(\xi_{r}-1\right) \phi_{0} x_{p}
$$

The prescribed displacement $\bar{u}_{b}\left(x_{p}\right)$ related to corrosion level $x_{p}$ will be considered as the boundary condition of the boundary-value problem for analysing concrete cracking development and predicting bond strength evolution. It is assumed here that uniform 
displacements are exerted around the bond interface to simplify the calculations, although reinforcement corrosion may start from the places close to the free surfaces of the concrete cover and thus the steel rebar may not corrode uniformly around the rebar surface at the beginning of natural corrosion (Xia et al. 2012). However, as pitting corrosion progresses, it appears as uniform corrosion in the later stage, as demonstrated in the long-term natural corrosion experimental studies by Zhang et al. (2010). The assumption for uniform expansive pressure at the bond interface is reasonable, as shown in many studies such as Balafas and Burgoyne (2011), Bhargava et al. (2008), Chen and Xiao (2012), Chernin et al. (2010) and Zhong et al. (2010).

\section{Concrete cracking model}

In order to analyse cover concrete cracking due to reinforcement corrosion, the thick-walled cylinder model shown in Fig. 1 has been frequently adopted such as in the studies by Bhargava et al. (2007), Chen and Alani (2013), Liu and Weyers (1998) and Wang and Liu (2004). This model can be considered as an axisymmetrical problem subject to the assumed uniform expansion, and could be further treated as a plane stress problem because the normal tensionsoftening stress in the direction of longitudinal axis can be ignored (Pantazopoulou and Papoulia 2001). Due to the expansive displacement applied around the bond surface, the hoop stress in the thick-walled cylinder is typically a principle tensile stress whereas the radial stress is a principle compressive stress. When the hoop stress reaches the tensile strength of concrete, the radial splitting cracks propagate from the bond interface $\left(R_{b}=\phi_{0} / 2\right)$ towards the free surface of concrete cover $\left(R_{c}=C+\phi_{0} / 2\right)$, as indicated in Fig. 1(b).

Concrete cracking could be modelled as a process of tension softening if the cracking is considered as cohesive and the crack width does not exceed a limited value in the fracture of 
concrete (Bažant and Planas 1998). In the cohesive crack model, the stress transferred through the cohesive cracks is assumed to be a function of crack opening (softening curve) to consider the plasticity and/or micro cracks in concrete. The behaviour of the cohesive cracks in concrete is defined by the relationship between the cohesive stress and the concrete crack width. The softening curve depends on the behaviour of concrete, e.g. concrete tensile strength, fracture energy, and ultimate crack width, which is affected by the heterogeneity of concrete such as the size of aggregates of concrete mix. In this study, the bilinear softening curve, described in CEB-FIP (1990) and shown in Fig. 2, is adopted, since this curve gives reasonable approximations for cracked concrete in tension (Bažant and Planas 1998), expressed here as

$$
\sigma_{w}=f_{t}(a-b W)
$$

where $\sigma_{w}$ is the tensile stress crossing cohesive cracks; $f_{t}$ is the maximum tensile strength of concrete at onset of cracking; $W$ is the normalised crack width defined as $W(r)=f_{t} w(r) / G_{f}$ in which $w(r)$ is the actual crack width at any radius $r$ and $G_{f}$ is the fracture energy of the concrete; coefficients $a$ and $b$, depending on the stage of crack width (pre-critical stage or postcritical stage), are given by

$$
\begin{gathered}
a=1, b=\frac{(1-\alpha)}{W_{c r}} \quad \text { if } 0 \leq W \leq W_{c r} \\
a=\frac{\alpha W_{u}}{\left(W_{u}-W_{c r}\right)}, \quad b=\frac{\alpha}{\left(W_{u}-W_{c r}\right)} \quad \text { if } W_{c r} \leq W \leq W_{u}
\end{gathered}
$$

in which coefficient $\alpha$, normalised critical crack width $W_{c r}$ (associated with actual critical crack width $w_{c r}$ ) and normalised ultimate cohesive crack width $W_{u}$ (associated with actual ultimate cohesive crack width $w_{u}$ ) can be determined from experiments for the concrete. In the CEBFIB Model Code, the coefficient $\alpha$ is given as $\alpha=0.15$ and $W_{c r}$ and $W_{u}$ could be evaluated from the tensile strength, fracture energy and maximum aggregate size of the concrete material 
(CEB-FIB 1990) to take the heterogeneity of concrete into account. The softening curve in Eq. (7) represents relationship between residual tensile strength and concrete crack width. Here, the effect of biaxial stress state due to the presence of principal stresses in hoop and radial directions on the cracking criteria and crack evolution law is not considered, since the principal compressive radial stress is typically much lower than the concrete compressive strength. The softening curve in Eq. (7) has been widely used in concrete fracture analyses, and research showed that the curve can give good estimations (Bažant and Planas 1998).

When cracking exists in the cover concrete, the total hoop strain $\varepsilon_{\theta}$ of the cracked concrete consists of fracture strain $\varepsilon_{\theta}{ }^{f}$ and linear elastic strain between cracks $\varepsilon_{\theta}{ }^{e}$. The fracture strain is generated by a total number of $n_{c}$ cracks, defined as $n_{c}=2 \pi R_{c} / L_{c}$ in which $L_{c}$ is minimum admissible crack band width estimated from $L_{c} \approx 3 d_{a}$ where $d_{a}$ is maximum aggregate size of concrete (Bažant and Planas 1998) to take the nature of concrete such as heterogeneity into account, whereas the linear elastic strain between cracks is associated with the residual tensile hoop stress $\sigma_{\theta}=\sigma_{w}$, defined, respectively, as

$$
\begin{gathered}
\varepsilon_{\theta}{ }^{f}=\frac{n_{c} w(r)}{2 \pi r}=b l_{0} \frac{f_{t}}{E} \frac{W}{r} \\
\varepsilon_{\theta}{ }^{e}=\frac{\sigma_{\theta}}{E}=\frac{f_{t}}{E}(a-b W)
\end{gathered}
$$

where $E$ is effective modulus of elasticity of intact concrete; $l_{0}$ is material coefficient defined as $l_{0}=n_{c} l_{c h} /(2 \pi b)$ in which $l_{c h}$ is characteristic length $l_{c h}=E G_{F} / f_{t}^{2}$ defined in Bažant and Planas (1998). The total hoop strain $\varepsilon_{\theta}$ of the cracked concrete is then given by

$$
\varepsilon_{\theta}=\varepsilon_{\theta}{ }^{f}+\varepsilon_{\theta}{ }^{e}=\frac{f_{t}}{E}\left[(a-b W)+b l_{0} \frac{W}{r}\right]
$$


The radial displacement $u$ of the cracked cover concrete for the axisymmetric problem is therefore calculated from

$$
u=\varepsilon_{\theta} r=\frac{f_{t}}{E}\left[(a-b W) r+b l_{0} W\right]
$$

For the cracked cover concrete modelled as axisymmetric elastic continuum, the governing equation for the thick-walled cylinder is given in Pantazopoulou and Papoulia (2001) as

$$
\frac{d^{2} u}{d r^{2}}+\frac{1}{r} \frac{d u}{d r}-\beta \frac{u}{r^{2}}=0
$$

where the reduction factor of residual tensile stiffness $\beta$ is defined here as

$$
\beta=\frac{E_{\theta}}{E}=\frac{\varepsilon_{\theta}{ }^{e}}{\varepsilon_{\theta}{ }^{e}+\varepsilon_{\theta}{ }^{f}}=\frac{(a-b W) r}{(a-b W) r+b l_{0} W}
$$

By utilising Eqs. (11) and (13), a new governing equation from Eq. (12) for directly solving the normalised crack width $W$ is constructed as

$$
\left(l_{0}-r\right) \frac{d^{2} W}{d r^{2}}+\left(l_{0}-3 r\right) \frac{1}{r} \frac{d W}{d r}=0
$$

The general solution to the second-order linear homogeneous differential equation is

$$
W=C_{1}\left[\frac{1}{l_{0}\left(l_{0}-r\right)}-\frac{1}{l_{0}^{2}} \ln \frac{\left|l_{0}-r\right|}{r}\right]+C_{2}
$$

where constant coefficients $C_{1}$ and $C_{2}$ in the general solution can be determined from two boundary conditions of the boundary-value problem, depending on the phase of crack development in the concrete. After the normalised crack width $W$ is obtained, the radial displacement $u$ over the thick-walled cylinder is calculated from Eq. (11). The radial strain over the cracked concrete is then given by 


$$
\varepsilon_{r}=\frac{d u}{d r}=\frac{f_{t}}{E}\left[(a-b W)+b\left(l_{0}-r\right) \frac{d W}{d r}\right]
$$

From the relationship between stress and strain with consideration of tensile stiffness reduction, the radial stress of the cracked concrete is expressed here as

$$
\sigma_{r}=\frac{E}{1-v^{2}}\left(\varepsilon_{r}+v \sqrt{\beta} \varepsilon_{\theta}\right)=\frac{f_{t}}{1-v^{2}}\left[(1+v \sqrt{\beta})(a-b W)+b\left(l_{0}-r\right) \frac{d W}{d r}+v \sqrt{\beta} b l_{0} \frac{W}{r}\right]
$$

where $v$ is Poisson's ratio. Consequently, the radial stress at the bond interface $\left(r=R_{b}\right)$ caused by the expansive reinforcement corrosion products is determined from Eq. (17).

\section{Concrete cracking development}

The process of bond strength evolution affected by reinforcement corrosion and concrete cracking can be generally divided into three phases, i.e. crack initiation phase, crack propagation phase and residual life phase. The crack initiation phase usually lasts relatively short period until corrosion-induced cracking initiates at the bond interface. As corrosion progresses, cracks propagates from the bond interface to the free concrete cover surface. With further corrosion of steel rebar, cracking widens through the concrete cover and finally reaches the ultimate cohesive width where the bond strength may lose completely.

\section{Crack initiation at bond interface}

Before cracking, intact concrete can be treated as isotropic elastic materials, hence the governing equation and stress distributions for the thick-walled cylinder given by Timoshenko and Goodier (1970) are used for the axisymmetric elastic continuum problem. The 
displacement boundary condition at the bond interface $\left(R_{b}\right)$ and the free surface condition at concrete cover surface $\left(R_{c}\right)$ are described here as

$$
\left.u\right|_{r=R_{b}}=\bar{u}_{b}\left(x_{p}\right),\left.\quad \sigma_{r}\right|_{r=R_{c}}=0
$$

where the prescribed displacement $\bar{u}_{b}\left(x_{p}\right)$ is related to corrosion level $x_{p}$, as given in Eq. (6). From the given boundary conditions with consideration of the volume expansion factor due to reinforcement corrosion, the radial and hoop stresses in the cover concrete can be obtained by Timoshenko and Goodier (1970), rewritten here as

$$
\begin{gathered}
\sigma_{r}=\frac{E R_{b}^{2}}{(1-v) R_{b}^{2}+(1+v) R_{c}^{2}}\left(1-\frac{R_{c}^{2}}{r^{2}}\right) \frac{\left(\xi_{r}-1\right)}{2} x_{p} \\
\sigma_{\theta}=\frac{E R_{b}^{2}}{(1-v) R_{b}^{2}+(1+v) R_{c}^{2}}\left(1+\frac{R_{c}^{2}}{r^{2}}\right) \frac{\left(\xi_{r}-1\right)}{2} x_{p}
\end{gathered}
$$

It is found that the hoop stress is in tension whereas the radial stress is in compression over the concrete cover. The cover concrete initiates cracking when the hoop stress $\sigma_{\theta}$ at the bond interface reaches the tensile strength $f_{t}$. From Eq. (19b), the corrosion level at the time when cracking initiates $\left(X_{p}^{I}\right)$ at the bond interface is estimated from

$$
X_{p}^{I}=\frac{2}{\left(\xi_{r}-1\right)} \frac{f_{t}}{E} \frac{(1-v)+(1+v)\left(1+2 C / \phi_{0}\right)^{2}}{1+\left(1+2 C / \phi_{0}\right)^{2}}
$$

The corrosion level for crack initiation at the bond interface largely depends on the rust volume expansion factor $\xi_{r}$ and the ratio of cover thickness to rebar diameter $C / \phi_{0}$. 
Due to the bilinear tension softening of the cover concrete two cases are considered, i.e. crack propagation before crack width at the bond interface reaches the critical value $\left(W_{b} \leq W_{c r}\right)$ and crack propagation when crack width at the bond surface exceeds the critical value $\left(W_{b} \succ W_{c r}\right)$.

\section{Case with $W_{b} \leq W_{c r}$}

Here, the thick-walled cylinder is divided into two zones, i.e. a cracked inner ring $\left(R_{b} \leq r \leq r_{y}\right)$ and an intact outer ring $\left(r_{y} \leq r \leq R_{c}\right)$ where $r_{y}$ is the radius of crack front. At the crack front $\left(r=r_{y}\right)$ the crack width is zero and the tensile hoop stress reaches the concrete tensile strength $f_{t}$. The boundary conditions for this case are expressed as

$$
\begin{gathered}
\left.u\right|_{r=R_{b}}=\bar{u}_{b}\left(x_{p}\right),\left.\quad W\right|_{r=r_{y}}=0 \text { for } R_{b} \leq r \leq r_{y} \\
\left.\sigma_{\theta}\right|_{r=r_{y}}=f_{t},\left.\quad \sigma_{r}\right|_{r=R_{c}}=0 \quad \text { for } r_{y} \leq r \leq R_{c}
\end{gathered}
$$

Define a general crack width function associated with material coefficient $l_{0}$ and radius $r$ within the thick-walled cylinder

$$
\delta\left(r_{1}, r_{2}\right)=\frac{r_{1}-r_{2}}{l_{0}\left(l_{0}-r_{1}\right)\left(l_{0}-r_{2}\right)}+\frac{1}{l_{0}^{2}} \ln \frac{r_{1}}{r_{2}} \frac{\left|l_{0}-r_{2}\right|}{\left|l_{0}-r_{1}\right|}
$$

By utilising the boundary conditions and the general solution for the normalised crack width in Eq. (15), the normalised crack width over the cracked inner ring is given by

$$
W=\frac{1}{(1-\alpha)\left(l_{0}^{c r}-R_{b}\right)}\left(\frac{E}{f_{t}} \bar{u}_{b}\left(x_{p}\right)-R_{b}\right) \frac{\delta^{c r}\left(r_{y}, r\right)}{\delta^{c r}\left(r_{y}, R_{b}\right)} W_{c r}
$$


where superscript $\mathrm{cr}$ in material coefficient $l_{0}$ and crack width function $\delta$ indicates that the material coefficient $l_{0}{ }^{c r}$ is calculated by using the coefficients of bilinear tension softening curve for the pre-critical stage in Eq. (8a). The crack front $\left(r_{y}\right)$ can be determined by utilising the continuity condition of radial stress crossing the intact and cracked zones, where the obtained normalised crack width in Eq. (23) is considered.

When the crack front reaches the concrete cover surface $\left(r_{y}=R_{c}\right)$, the corresponding corrosion level at the time to crack on the concrete cover surface $X_{p}^{C}$ is determined, from Eq. (23) and by using the normalised crack width at the bond interface, by

$$
X_{p}^{C}=\frac{2}{\left(\xi_{r}-1\right)} \frac{f_{t}}{E}\left(1+(1+v)\left(1+2 \frac{C}{\phi_{o}}\right) \eta_{x}^{c r}\left(R_{c}, R_{b}\right)\right)
$$

where coefficient $\eta_{x}^{c r}\left(R_{c}, R_{b}\right)$ is determined by the general coefficient $\eta_{x}\left(R_{c}, R_{b}\right)=\left(l_{0}-R_{b}\right)\left(l_{0}-R_{c}\right) \delta\left(R_{c}, R_{b}\right)$ by using $l_{0}=l_{0}^{c r}$. From Eq. (24), the corrosion level at the time when cracks reach the cover surface depends concrete properties, rust volume expansion factor $\xi_{r}$ and the ratio of cover thickness to rebar diameter $C / \phi_{0}$.

\section{Case with $W_{b} \succ W_{c r}$}

The thick-walled cylinder is now divided into three zones shown in Fig. 1(b), a cracked inner ring where crack width exceeds critical value $\left(R_{b} \leq r \leq r_{c r}\right)$ where $r_{c r}$ is radius of critical crack boundary, a cracked middle ring where crack width does not exceed critical value $\left(r_{c r} \leq r \leq r_{y}\right)$ and an intact outer ring $\left(r_{y} \leq r \leq R_{c}\right)$. In this case, the boundary conditions are expressed as

$$
\left.u\right|_{r=R_{b}}=\bar{u}_{b}\left(x_{p}\right),\left.\quad W\right|_{r=r_{c r}}=W_{c r} \quad \text { for } \quad R_{b} \leq r \leq r_{c r}
$$




$$
\begin{gathered}
\left.W\right|_{r=r_{c r}}=W_{c r},\left.\quad W\right|_{r=r_{y}}=0 \text { for } r_{c r} \leq r \leq r_{y} \\
\left.\sigma_{\theta}\right|_{r=r_{y}}=f_{t},\left.\quad \sigma_{r}\right|_{r=R_{c}}=0 \quad \text { for } r_{y} \leq r \leq R_{c}
\end{gathered}
$$

By implementing these boundary conditions and utilising the general solution in Eq. (15), the normalised crack widths over the cracked inner ring and within the cracked middle ring are given, respectively, by

$$
\begin{gathered}
W=\frac{1}{\alpha\left(l_{0}^{u}-R_{b}\right)}\left(\frac{E}{f_{t}} \bar{u}_{b}\left(x_{p}\right)-\frac{\alpha W_{u}}{\left(W_{u}-W_{c r}\right)} R_{b}\right) \frac{\delta^{u}\left(r_{c r}, r\right)}{\delta^{u}\left(r_{c r}, R_{b}\right)}\left(W_{u}-W_{c r}\right)+\frac{\delta^{u}\left(r, R_{b}\right)}{\delta^{u}\left(r_{c r}, R_{b}\right)} W_{c r} \\
\quad \text { for } R_{b} \leq r \leq r_{c r} \\
W=\frac{\delta^{c r}\left(r_{y}, r\right)}{\delta^{c r}\left(r_{y}, r_{c r}\right)} W_{c r} \quad \text { for } r_{c r} \leq r \leq r_{y}
\end{gathered}
$$

where superscript $u$ in material coefficient $l_{0}$ and crack width function $\delta$ represents that the material coefficient $l_{0}{ }^{u}$ is calculated by the post-critical coefficients in Eq. (8b). The crack front $\left(r_{y}\right)$ and the critical crack boundary $\left(r_{c r}\right)$ are obtained from additional two boundary conditions of the continuity of radial stresses at both the crack front and at the critical crack boundary, where the relevant normalised crack width in Eq. (26) is considered.

By using the obtained crack width at the bond interface, the corrosion level at the time to crack on the cover surface for this case $X_{p}^{C}$ is estimated by

$$
X_{p}^{C}=\frac{2}{\left(\xi_{r}-1\right)} \frac{f_{t}}{E} \frac{\alpha W_{u}}{\left(W_{u}-W_{c r}\right)}\left(1+\frac{\left(l_{0}^{u}-R_{b}\right)}{R_{b}} \frac{W_{c r}}{W_{u}}+\frac{1-\alpha}{\alpha} \frac{\left(l_{0}^{c r}-R_{c}\right)}{R_{b}} \frac{\eta_{x}^{u}\left(r_{c r}^{c}, R_{b}\right)}{\eta_{x}^{c r}\left(R_{c}, r_{c r}^{c}\right)} \frac{\left(W_{u}-W_{c r}\right)}{W_{u}}\right)
$$


where $\eta_{x}^{u}$ is determined by the general coefficient $\eta_{x}$ in which $l_{0}=l_{0}{ }^{u}$, as discussed in Eq. (24). At the time to crack on the cover surface, the crack front is taken as $r_{y}=R_{c}$ and the critical crack boundary $r_{c r}^{c}$ is given by

$$
(1+v) R_{c}\left(l_{0}^{c r}-R_{c}\right) \delta^{c r}\left(R_{c}, r_{c r}^{c}\right)=1-\alpha
$$

Here again, the corrosion level at the time to crack is a function of concrete properties, rust volume expansion factor and the ratio of cover thickness to rebar diameter.

\section{Completely cracked concrete cover}

After crack front reaches the cover surface, the concrete cover becomes completely cracked. Depending on the crack widths at the bond interface $W_{b}$ and at the cover surface $W_{c}$, three cases are considered, i.e. crack width over the concrete cover does not exceed the critical value $\left(W_{b} \leq W_{c r}\right.$ and $\left.W_{c} \leq W_{c r}\right)$, critical crack width propagates through the concrete cover $\left(W_{b} \succ W_{c r}\right.$ and $W_{c} \prec W_{c r}$ ), and crack width over the concrete cover exceeds the critical value $\left(W_{b} \succ W_{c r}\right.$ and $W_{c} \succ W_{c r}$ ).

Case with $W_{b} \leq W_{c r}$ and $W_{c} \leq W_{c r}$

Here, a single cracked zone within the concrete cover exists, and the crack width at the bond interface does not exceed the critical value at the time to crack. The boundary conditions described in Eq. $(18 \mathrm{a}, \mathrm{b})$ are used for this case. By introducing the boundary conditions and ignoring the Poisson's effect associated with the hoop strain due to completely cracked concrete, the normalised crack width on the concrete cover surface $W_{c}$ is obtained from 


$$
W_{c}=\frac{1}{(1-\alpha) \eta_{w}^{c r}\left(R_{c}, R_{b}\right)}\left(\frac{1}{2}\left(\xi_{r}-1\right) \frac{E}{f_{t}} R_{b} x_{p}-R_{b}-R_{c} \eta_{x}^{c r}\left(R_{c}, R_{b}\right)\right) W_{c r}
$$

where coefficient $\eta_{w}^{c r}\left(R_{c}, R_{b}\right)$ is determined by the general coefficient $\eta_{w}\left(R_{c}, R_{b}\right)=\left(l_{0}-R_{b}\right)\left[1-R_{c}\left(l_{0}-R_{c}\right) \delta\left(R_{c}, R_{b}\right)\right]$ by using $l_{0}=l_{0}{ }^{c r}$. The normalised crack width over the concrete cover is then expressed as

$$
W=\frac{1}{(1-\alpha)\left(l_{0}^{c r}-R_{b}\right)}\left(\frac{E}{f_{t}} \bar{u}_{b}\left(x_{p}\right)-R_{b}\right) \frac{\delta^{c r}\left(R_{c}, r\right)}{\delta^{c r}\left(R_{c}, R_{b}\right)} W_{c r}+\frac{\delta^{c r}\left(r, R_{b}\right)}{\delta^{c r}\left(R_{c}, R_{b}\right)} W_{c}
$$

Case with $W_{b} \succ W_{c r}$ and $W_{c} \prec W_{c r}$

The critical crack front divides the thick-walled cylinder into two zones, a cracked inner ring where crack width exceeds the critical value $\left(R_{b} \leq r \leq r_{c r}\right)$ and a cracked outer ring where crack width does not exceed the critical value $\left(r_{c r} \leq r \leq R_{c}\right.$ ), giving the boundary conditions as

$$
\begin{gathered}
\left.u\right|_{r=R_{b}}=\bar{u}_{b}\left(x_{p}\right),\left.\quad W\right|_{r=r_{c r}}=W_{c r} \text { for } R_{b} \leq r \leq r_{c r} \\
\left.W\right|_{r=r_{c r}}=W_{c r},\left.\quad \sigma_{r}\right|_{r=R_{c}}=0 \quad \text { for } r_{c r} \leq r \leq R_{c}
\end{gathered}
$$

From these boundary conditions, the normalised crack width at the concrete cover surface $W_{c}$ is given as

$$
W_{c}=\frac{1}{(1-\alpha) \eta_{w}^{c r}\left(R_{c}, r_{c r}\right)}\left[(1-\alpha)\left(l_{0}^{c r}-r_{c r}\right)-R_{c} \eta_{x}^{c r}\left(R_{c}, r_{c r}\right)\right] W_{c r}
$$

where the critical crack boundary $\left(r_{c r}\right)$ between the outer ring and the inner ring is obtained from the continuity condition of radial stresses crossing two rings. The normalised crack width within the cracked inner ring is then calculated from 


$$
W=\left[\frac{1}{(1-\alpha)\left(l_{0}^{u}-R_{b}\right)}\left(\frac{E}{f_{t}} \bar{u}_{b}\left(x_{p}\right)-R_{b}\right) \delta^{u}\left(r_{c r}, r\right)+\delta^{u}\left(r, R_{b}\right)\right] \frac{W_{c r}}{\delta^{u}\left(r_{c r}, R_{b}\right)}
$$

Case with $W_{b} \succ W_{c r}$ and $W_{c} \succ W_{c r}$

The crack width over the concrete cover now exceeds the critical value, and the boundary conditions for this case are given in Eq. (18a,b). From the boundary conditions, the normalised crack width at cover surface $W_{c}$ is obtained from

$$
W_{c}=\frac{1}{\eta_{w}^{u}\left(R_{c}, R_{b}\right)}\left(\frac{1}{2}\left(\xi_{r}-1\right) \frac{E}{f_{t}} \frac{\left(W_{u}-W_{c r}\right)}{\alpha W_{u}} R_{b} x_{p}-R_{b}-R_{c} \eta_{x}^{u}\left(R_{c}, R_{b}\right)\right) W_{u}
$$

where coefficient $\eta_{w}^{u}\left(R_{c}, R_{b}\right)$ is determined by general coefficient $\eta_{w}\left(R_{c}, R_{b}\right)$ in which $l_{0}=l_{0}{ }^{u}$

. The normalised crack width within the cracked concrete cover is expressed as

$$
W=\frac{1}{\alpha\left(l_{0}^{u}-R_{b}\right)}\left(\frac{E}{f_{t}} \bar{u}_{b}\left(x_{p}\right)-\frac{\alpha W_{u}}{\left(W_{u}-W_{c r}\right)} R_{b}\right) \frac{\delta^{u}\left(R_{c}, r\right)}{\delta^{u}\left(R_{c}, R_{b}\right)}\left(W_{u}-W_{c r}\right)+\frac{\delta^{u}\left(r, R_{b}\right)}{\delta^{u}\left(R_{c}, R_{b}\right)} W_{c}
$$

The corrosion level at the time when cracks in the cover concrete reach the ultimate cohesive width $\left(X_{p}^{U}\right)$ is determined by

$$
X_{p}^{U}=\frac{2}{\pi\left(\xi_{r}-1\right)} \frac{f_{t}}{E} \frac{n_{c} l_{c h}}{\phi_{o}} W_{u}
$$

Similarly, the corrosion level at the time for cracks to reach ultimate cohesive width is related to material properties and rust volume expansion factor.

\section{Ultimate bond strength}


The bond strength of plain bars relies on adhesion and friction between rebar and the surrounding concrete, whereas the bond strength of deformed bars, which are most commonly used in RC structures and are mainly concerned in this study, depends on adhesion, friction and mechanical interlocking as well. Reinforcement corrosion affects the bond properties between rebar and the surrounding concrete by changing the shape and angle of the ribs of deformed rebar. Corrosion also influences the mechanical interlocking between rebar and the surrounding concrete by reducing adhesion and frictional force due to the accumulation of corrosion products. To consider these effects, Coronelli (2002) proposed a analytical model to evaluate the ultimate bond strength of corroded reinforcement by modifying the original model provided by Cairns and Abdullah (1996). From the modified model, the ultimate bond strength is obtained from the total contribution of three types of stresses acting at the bond interface, i.e. adhesion, confinement and corrosion pressure.

The adhesion strength at bond interface $\left(T_{a d h}\right)$ is related to interface cohesion, defined as non-splitting component associated with the friction and adhesion stress acting on inclined rib faces, is given by Coronelli (2002) as a function of corrosion level

$$
T_{a d h}\left(x_{P}\right)=\frac{n_{s t} A_{b}\left(x_{P}\right) f_{c o h}\left(x_{P}\right)\left[\cot \delta_{o}+\tan \left(\delta_{o}+\varphi\right)\right]}{\pi \phi_{r}\left(x_{P}\right) S_{r}}
$$

where $n_{s t}$ is the number of stirrups; $A_{b}=\pi h_{r} \phi_{r}\left(x_{P}\right)$ is the rib area in plane at right angle to bar axis and $h_{r}=0.07 \phi_{r}$ is the reduced rib height of the rebar at corrosion level $x_{P}$; the coefficient of adhesion stress $f_{\text {coh }}$ is taken as $f_{\text {coh }}=2-10\left(x-x_{c}\right)$ in which $x_{c}$ is the corrosion attack penetration $x$ corresponding to the corrosion level at the time to $\operatorname{crack}\left(X_{p}^{C}\right)$; $\delta_{o}$ is the orientation of rib taken as $45^{\circ} ; \varphi$ is the angle of friction between rebar and concrete; $\tan \left(\delta_{o}+\varphi\right)$ can be estimated from $1.57-0.785 x$ and $S_{r}$ is the rib spacing taken as $0.6 \phi_{r}$ (Wang and Liu 2004). 
The confinement strength $\left(T_{c n f}\right)$ from the surrounding concrete and steel stirrups is expressed in Giuriani et al. (1991) as

$$
T_{c n f}\left(x_{P}\right)=\frac{1}{\pi} n_{s t} C_{r} \tan \left(\delta_{o}+\emptyset\right) \sigma_{c n f}\left(x_{P}\right)
$$

where $C_{r}$ is the shape factor constant taken as 0.8 for crescent shape rebar. The maximum confinement stress $\sigma_{c n f}$ at bond failure, related to reinforcement corrosion level $x_{P}$, is contributed from the confining action of both the cracked concrete $\sigma_{c n f, c}$ and the steel stirrups $\sigma_{c n f, s t}$. In order to consider the influence of reinforcement corrosion on the confinement contribution from the surrounding cracked concrete and the steel stirrups, the original relations proposed by Giuriani et al. (1991) are modified here, respectively, as

$$
\begin{gathered}
\sigma_{c n f, c}\left(x_{P}\right)=\frac{2\left[C-\bar{u}_{b}\left(x_{P}\right)\right]}{\phi_{r}\left(x_{P}\right)} \frac{1-w_{b}\left(x_{P}\right) / w_{c r}}{1+k_{c} w_{b}\left(x_{P}\right) / d_{a}} f_{t} \\
\sigma_{c n f, s t}\left(x_{P}\right)=\frac{n_{s t} A_{s t}}{\phi_{r}\left(x_{P}\right) \Delta z}\left(\frac{a_{2} w_{b}^{2}\left(x_{P}\right)}{\alpha_{s}^{2} d_{s t}^{2}}+\frac{a_{1} w_{b}\left(x_{P}\right)}{\alpha_{s} d_{s t}}+a_{o}\right)^{1 / 2} E_{s t}
\end{gathered}
$$

where $w_{b}\left(x_{P}\right)=G_{f} W_{b}\left(x_{P}\right) / f_{t}$ is the actual crack width on the rebar surface at corrosion level $x_{p}$ in which the associated normalised crack width $W_{b}$ can be obtained from the discussion in preceded section for concrete crack development; $k_{c}$ is the constant taken as $167 ; A_{s t}$ is the cross-sectional area of stirrup leg; $\Delta z$ is the spacing of stirrup; $\alpha_{s}$ is the shape factor of stirrup taken as 2; coefficients $a_{o}, a_{1}$ and $a_{2}$ are related to trilateral local bond-slip law of stirrups; $d_{s t}$ is the diameter of stirrup leg; and $E_{s t}$ is the modulus of elasticity of steel stirrups. In this study, the confinement strength is analytically expressed as a function of corrosion level $x_{P}$. Also, the limited confinement contribution from stirrups is considered, as suggested in many design codes such as CEB-FIP (1990) and ACI Committee 408R (2003). 
The bond strength contributed from corrosion pressure due to reinforcement corrosion $\left(T_{c o r r}\right)$ is expressed in Coronelli (2002) as

$$
T_{\text {corr }}\left(x_{P}\right)=\mu\left(x_{P}\right) \sigma_{c o r r}\left(x_{P}\right)
$$

where $\mu$ is the coefficient of friction between the corroded rebar and the cracked concrete taken as $\mu=0.37-0.26\left(x-x_{c}\right)$. Corrosion pressure $\sigma_{c o r r}\left(x_{P}\right)$ is the radial pressure exerted by expansive corrosion products at the bond interface and defined in general equation Eq. (17), which can be determined from the discussion for various phases in the preceded section. In the phase before cracking initiates at the bond interface, the radial pressure is estimated from Eq. (19a). During the period of crack propagation from the bond interface to the concrete cover, in the case when crack width at the bond interface does not exceed the critical value ( $\left.0<W_{b} \leq W_{c r}\right)$, the radial corrosion pressure $\sigma_{c o r r}$ is expressed here as

$$
\sigma_{c o r r}=\frac{f_{t}}{1-v^{2}}\left[\left(1+v \sqrt{\beta_{b}^{c r}}\right)\left(1-(1-\alpha) \frac{W_{b}}{W_{c r}}\right)+(1-\alpha)\left(l_{0}^{c r}-R_{b}\right) W_{, r}^{c r}+v(1-\alpha) \sqrt{\beta_{b}^{c r}} \frac{l_{0}^{c r}}{R_{b}} \frac{W_{b}}{W_{c r}}\right]
$$

where $\beta_{b}^{c r}$ is the reduction factor of concrete residual tensile stiffness at the bond interface in which $l_{0}=l_{0}{ }^{c r}$, and $W_{, r}^{c r}$ is the first derivative of the normalised crack width with respect to radius $r$ at the bond interface in which $l_{0}=l_{0}{ }^{c r}$. In the case when crack width at the bond interface exceeds the critical value $W_{c r}<W_{b} \leq W_{u}$, the radial stress is rewritten here as

$$
\sigma_{c o r r}=\frac{f_{t}}{1-v^{2}} \frac{\alpha}{\left(W_{u}-W_{c r}\right)}\left[\left(1+v \sqrt{\beta_{b}^{u}}\right)\left(W_{u}-W_{b}\right)+\left(l_{0}^{u}-R_{b}\right) W_{, r}^{u}+v \sqrt{\beta_{b}^{u}} \frac{l_{0}^{u}}{R_{b}} W_{b}\right]
$$

where $\beta_{b}^{u}$ and $W_{, r}^{u}$ are related to post-critical material coefficient $l_{0}=l_{0}{ }^{u}$. From the obtained corrosion pressure at the bond interface, the corrosion strength can be estimated from Eq. (40). 


\section{Model evaluation and application}

In order to demonstrate the effectiveness of the proposed analytical model for predicting the bond strength evolution due to reinforcement corrosion, numerical examples for corrosion affected RC structures are employed and the predicted results are then compared with relevant experimental data available from various sources. Since the corrosion-induced bond strength evolution is strongly related to crack development in the cover concrete, the crack width growth with increase of corrosion level is investigated initially. In this study, crack width in the cover concrete is represented by the equivalent crack width, defined in Zhang et al. (2010) as the cumulated crack width over the cover.

The results in Fig. 3 show the analytically predicted development of crack width on the concrete cover surface as a function of corrosion level $x_{P}$. The analytical predictions are then compared with the experimental data by Alonso et al. (1998) with various concrete cover thicknesses. In their study, the experiments were performed by an accelerated corrosion test with corrosion rate of $100 \mu \mathrm{A} / \mathrm{cm}^{2}$ on two sets of small reinforced beams, i.e. one set with dimensions of $15 \times 15 \times 38 \mathrm{~cm}$, rebar diameter of $14 \mathrm{~mm}$ and clear cover thickness of $25 \mathrm{~mm}$ (smaller cover thickness) and another set with dimensions of $30 \times 30 \times 30 \mathrm{~cm}$, rebar diameter of $16 \mathrm{~mm}$ and clear cover thickness of $62 \mathrm{~mm}$ (larger cover thickness). A tensile strength of the concrete was taken in their study as $f_{t}=3.3 \mathrm{MPa}$, which is adopted here to estimate other parameters of the concrete in the calculations, such as concrete compressive strength by $f_{c}=$ $2.10 f_{t}^{2}=22.9 \mathrm{MPa}$, elastic modulus $E=4400\left(f_{c}\right)^{0.516}=22.1 \mathrm{GPa}$ and Poisson's ratio $v=0.18$ (Stewart and Rosowsky 1998). Other relevant material properties adopted in the predictions are evaluated from the given concrete properties with assumed maximum aggregate size $d_{a}=25 \mathrm{~mm}$, such as fracture energy $G_{f}=76 \mathrm{~N} / \mathrm{m}$, total crack number $n_{c}=4$, critical equivalent crack width $w_{c r}=0.12 \mathrm{~mm}$, and ultimate cohesive equivalent crack width 
$w_{u}=0.8 \mathrm{~mm}$ (CEB-FIP 1990; Pantazopoulou and Papoulia 2001). The volume expansion factor due to expansive reinforcement corrosion products is taken as $\xi_{r}=3.83$ (Liu and Weyers 1998). From the results in Fig. 3, the predicted crack widths as a function of corrosion level are in good agreement with the experimental data by Alonso et al. (1998) for both cases with smaller and larger concrete cover thicknesses. In the case with smaller cover thickness, reinforcement corrosion at lower level of $0.6 \%$ causes concrete cracking on the cover surface, while in the case with larger concrete cover thickness, a higher corrosion level of $1.4 \%$ is required for cracks to propagate to the cover surface. After the cover concrete is completely cracked, the crack width has an approximately linear relation with corrosion level, which agrees with the results from many experimental studies including in Zhang et al. (2010).

The results in Fig. 4 show the comparison of predicted corrosion pressure at the bond interface with analytical results by Pantazopoulou and Papoulia (2001) and Bhargava et al. (2007). The results are obtained for the experimental sample S2 in Liu and Weyers (1998) with cover thickness $C=70 \mathrm{~mm}$, compressive strength $f_{c}=31.5 \mathrm{MPa}$, corrosion rate $i_{\text {corr }}=1.79 \mu \mathrm{A} /$ $\mathrm{cm}^{2}$ and rebar diameter $\phi_{o}=16 \mathrm{~mm}$. Here again, other parameters required in the proposed model are estimated by using methods given in Stewart and Rosowsky (1998) and CEB-FIP (1990). From the results in Fig. 4, the predicted bursting pressure exerted by the accumulation of the corrosion products at the bond interface has a maximum value of $17.9 M P a$ at the corrosion level of $0.66 \%$ at the time when crack front propagates to about $2 / 3$ of the cover. When cracking approaches the cover surface, a sudden release of the corrosion pressure takes place and the residual pressure maintains only less than a third of the maximum value. As corrosion further progresses the corrosion pressure gradually decays to zero until crack width reaches the ultimate cohesive value. The bursting pressure predicted by Pantazopoulou and Papoulia (2001) gives a close maximum value but vanishes completely once crack front reaches the cover surface, since the residual stength of the cracked cover concrete is not 
considered in their study. The prediction of radial pressure by Bhargava et al. (2007) increases steadily as conrrosion level increases, without considering the effects of cracking in the surrounding concrete and the tension softening of the cracked concrete. As demonstrated in the experimental investigations by Law et al. (2011), substantial residual bond strength exists for both with and without steel stirrups after cracks appear on the cover surface, and then the bond strength gradually decreases to a smaller value even at concrete crack width of $1.4 \mathrm{~mm}$. Therefore, the proposed analytical model gives more appropriate predictions for corrosion pressure at the bond interface since the realistic properties of the cracked concrete, such as anisotripic behaviour, cohesive cracking, residual tensile strength and reduced tensile stiffness, are considered in the proposed model.

The proposed analytical model now gives the evolution of bond strength as reinforcement corrosion progresses. The predicted results are compared with various published experimental results given by Rodriguez et al. (1994) and Lee et al. (2002), as shown in Figs. 5-7. Rodriguez et al. (1994) conducted experiments to measure the bond strength of concrete specimens with and without steel stirrups due to rebar corrosion. In their experiments, confined specimens were prepared with stirrups of a diameter of $6 \mathrm{~mm}$ at spacing of $100 \mathrm{~mm}$. The dimensions of the concrete cube specimens were measured as $300 \mathrm{~mm}$, and four bars of a diameter of $16 \mathrm{~mm}$ were placed at the four corners of the cube with clear cover thickness of $24 \mathrm{~mm}$. The compressive strength of concrete was taken as $40 M P a$, which is used for estimating other concrete parameters required in the calculations. Similarly, Lee et al. (2002) undertook the pull-out tests to study rebar corrosion induced bond strength deterioration. A single bar of a diameter of $13 \mathrm{~mm}$ was centrally embedded in the concrete cube of $65 \mathrm{~mm}$ in dimensions with a clear cover of $39 \mathrm{~mm}$. The compressive strength of concrete was measured $42.1 \mathrm{MPa}$, which is again adopted for evaluating necessary concrete parameters for calculations. 
Fig. 5 shows the predicted results for the ultimate bond strength and its components, contributed by adhesion, confinement and corrosion pressure, as a function of corrosion level. The predicted ultimate bond strength matches well with the experimental results without stirrups by Rodriguez et al. (1994) at various corrosion levels. From the results, the confinement and the corrosion pressure have major contributions to the ultimate bond strength. As reinforcement corrosion progresses, the relatively small contribution of adhesion stress gradually decreases to zero, while the contribution of confinement from the surrounding concrete drops fast at low corrosion level and then gently vanishes at high corrosion level. This may be due to many facts caused by the reinforcement corrosion and concrete cracking, such as reduction in geometrical properties of the ribs of deformed rebar, deterioration of mechanical interlocking caused by accumulating corrosion products, growth of concrete crack width at the rebar surface, and decrease in the residual strength of the cracked concrete. However, the contribution of corrosion pressure at the bond interface increases in the early stage of the crack propagation phase, but has a sharp drop when concrete cracking approaches the cover surface and then gradually decays with increase of corrosion level. The reason for the initial increase of corrosion pressure contribution is that the bursting stress at the rebar surface caused by the expansive corrosion products increases in the early stage of crack propagation phase, as shown in Fig. 4, and the roughness of rebar may also increase in this stage. As corrosion level further increases, the corrosion pressure contribution decreases gradually to zero at the corrosion level of approximately $10 \%$ when cracks reaches the ultimate cohesive width.

The results in Fig. 6 show the ultimate bond strength evolution related to reinforcement corrosion for the specimens with stirrups (confined) and without stirrups (unconfined). The analytically predicated results from the proposed model are then compared with experimental data by Rodriguez et al. (1994). From the obtained results, the bond strength of the rebar increases for both confined and unconfined cases at low corrosion level $\left(x_{p}<0.4 \%\right)$. During the 
period when cracking approaches the cover surface, abrupt decrease of the bond strength takes place for both confined and unconfined cases. Larger decrease in the ultimate bond strength occurs for the unconfined case due to the reduced confinement from the cracked concrete and the absence of confinement from stirrups. Residual bond strength still exists for confined case when concrete crack reaches the ultimate cohesive width.

The results for the ultimate bond strength predicted by the proposed analytical model are now further compared with the experimental data by Lee et al. (2002) and analytical results by Bhargava et al. (2007), as shown in Fig. 7. Similar curve for the ultimate bond strength evolution is obtained from the proposed model as reinforcement corrosion progresses. The results show that the proposed analytical model can provide predictions in better agreement with the experimental data, comparing with the analytical results by Bhargava et al. (2007). Again, this is because the proposed model adopts more realistic estimates of concrete properties, by considering the anisotropic nature of the cracked concrete and the influence of concrete crack growth.

\section{Conclusions}

A new analytical model for predicting the ultimate bond strength evolution in corrosion damaged RC structures is proposed on the basis of the thick walled cylinder model and the use of realistic concrete properties. The proposed model can provide reliable results for residual bond strength as reinforcement corrosion progresses, which agree well with the experimental data available from various sources. From the results obtained by the proposed analytical

model, following conclusions can be drawn: 1) The process of bond strength evolution caused by reinforcement corrosion can be described as three phases associated with crack development in the cover concrete, i.e. crack initiation phase, crack propagation phase and residual life 
phase; 2) The corrosion-induced concrete crack width has an approximately linear relation with corrosion level, and the corrosion level associated with each phase of crack development can be determined by the proposed model; 3) The ultimate bond strength increases at low level of reinforcement corrosion (typically less than 1\%) during the crack propagation phase, but decreases significantly when concrete cracking propagates to the cover surface and then gradually decays to zero at the time when crack reaches the ultimate cohesive width; 4) The confinement from steel stirrups makes significant contribution to the ultimate bound strength, in particular to the residual bond strength during the residual life phase when the cover concrete is completely cracked.

\section{References}

ACI (2003). Bond and development of straight reinforcing bars in tension, American Concrete Institute, Committee 408R, 1-49.

Alonso, C., Andrade, C., Rodriguez, J., and Diez, J. M. (1998). "Factors controlling cracking of concrete affected by reinforcement corrosion.” Mater. Struct., 31, 435-441.

Amleh, L., and Ghosh, A. (2006). "Modeling the effect of corrosion on bond strength at the steel-concrete interface with finite element analysis." Can. J. Civ. Eng., 33(6), 673-682.

Auyeung, Y., Balaguru, P., and Chung, L. (2000). "Bond behaviour of corroded reinforcement bars." ACI Mater. J., 97(2), 214-221.

Balafas, I., and Burgoyne, C. J. (2011). "Modeling the structural effects of rust in concrete cover.” J. Eng. Mech., ASCE, 137(3), 175-185.

Bažant, Z. P., and Planas, J. (1998). Fracture and size effect in concrete and other quasibrittle materials, CRC Press, Boca Raton, Florida USA.

Bhargava, K., Ghosh, A. K., Mori, Y., and Ramanujam, S. (2007). "Corrosion-induced bond strength degradation in reinforced concrete: Analytical and empirical models." Nucl. Eng. Des., 237, 1140-1157. 
Bhargava, K., Ghosh, A. K., Mori, Y., and Ramanujam, S. (2008). "Suggested empirical models for corrosion-induced bond degradation in reinforced concrete." J. Struct. Eng., ASCE, 134(2), 221-230.

Budiansky, B., and Hutchinson, J. W. (1986). "Matrix fracture in fiber-reinforced ceramic." J. Mech. Phys. Solids, 34(2), 167-189.

Cairns, J., and Abdullah, R. B. (1996). "Bond strength of black and epoxy-coated einforcement - a theoretical approach.” ACI Mater. J., 93(4), 362-369.

Chen, H. P., and Alani, A. M. (2013). "Optimized maintenance strategey for concrete structures affected by cracking due to reinforcement corrosion.” ACI Struct. J., 110(2), 229238.

Chen, H. P., and Xiao, N. (2012).“Analytical solutions for corrosion-induced cohesive concrete cracking.” J. Appl. Math., Article ID 769132.

Chernin, L., Val, D. V., and Volokh, K. Y. (2010). “Analytical modelling of concrete cover cracking caused by corrosion of reinforcement." Mater. and Struct., 43(4), 543-556.

Comité Euro-international du Béton - Fédération International de la Précontrainte (CEB-FIP). (1990). Design code, Thomas Telford, London.

Coronelli, D. (2002). "Corrosion cracking and bond strength modelling for corroded bars in reinforced concrete.” ACI Struct. J., 99(3), 267-276.

Fang, C., Lundgren, K., Chen, L., and Zhu, C. (2004). "Corrosion influence on bond in reinforced concrete." Cem. and Conc. Res., 34(11), 2159-2167.

FIB. (2000). Bond of reinforcement in concrete-State of the art report, Bulletin 10, TG4/2 (Bond Models), FIB, Lausanne, Switzerland.

Giuriani, E., Plizzari, G., and Schumm, C. (1991). "Role of stirrups and residual tensile strength of cracked concrete on bond." J. Struct. Eng., ASCE, 117(1), 1-18.

Ho, S., and Suo, Z. (1992). "Microcracks tunneling in brittle matrix composites driven by thermal expansion mismatch." Acta Metall. Mater., 40(7), 1685-1690.

Law, D. W., Tang, D., Molyneaux, T. K. C., and Gravina, R. (2011). “Impact of crack width on bond: confined and unconfined rebar." Mater. and Struct., 44(7), 1287-1296. 
Lee, H. S., Noguchi, T., and Tomosawa, F. (2002). "Evaluation of the bond properties between concrete and reinforcement as a function of the degree of reinforcement corrosion." Cem. and Conc. Res., 32(8), 1313-1318.

Liu, Y., and Weyers, R. E. (1998). "Modeling the time-to-corrosion cracking in chloride contaminated reinforced concrete structures." ACI Mater. J., 95(6), 675-680.

Lundgren, K. (2002). "Modelling the effect of corrosion on bond in reinforced concrete." Mag. Conc. Res., 54(3), 165-173.

Pantazopoulou, S., and Papoulia, K. D. (2001). "Modeling cover-cracking due to reinforcement corrosion in RC structures." J. Eng. Mech., ASCE, 127(4), 342-351.

Rodriguez, J., Ortega, L. M., and Casal, J. J. (1994). "Corrosion of reinforcing bars and service life of reinforced concrete structures: corrosion and bond deterioration." Proc. Concrete across Borders, Vol.II, Odense, Denmark, 315-326.

Stanish, K., Hooton, R. D., and Pantazopoulou, S. J. (1999). "Corrosion effects on bond strength in reinforced concrete.” ACI Struct. J., 96(6), 915-921.

Stewart, M. G., and Rosowsky, D. V. (1998). "Time-dependent reliability of deteriorating reinforced concrete bridge decks." Struct. Saf., 20(1), 91-109.

Timoshenko, S. P., and Goodier, J. N. (1970). Theory of Elasticity, 3rd Ed., McGraw-Hill, New York.

Wang, X., and Liu, X. (2004). "Modelling effects of corrosion on cover cracking and bond in reinforced concrete." Mag. Conc. Struct., 56(4), 191-199.

Vidal, T., Castel, A., and Francois, R. (2004). "Analyzing crack width to predict corrosion in reinforced concrete." Cem. and Conc. Res., 34(1), 165-174.

Xia, N., Ren, Q., Robert, Y., Liang, J. P., and Patnaik, A. (2012). "Nonuniform corrosioninduced stresses in steel-reinforced concrete.” J. Eng. Mech., ASCE, 138(4), 338-346.

Zhang, R., Castel, A., and François, R. (2010). "Concrete cover cracking with reinforcement corrosion of RC beam during chloride-induced corrosion process." Cem. and Conc. Res., 40(3), 415-425. 
Zhong, J., Gardoni, P., and Rosowsky, D. (2010). "Stiffness degradation and time to cracking of cover concrete in reinforced concrete structures subject to corrosion." J. Eng. Mech., ASCE, 136(2), 209-219. 


\section{Figure Captions}

Fig. 1. Idealisation of cover concrete as thick-walled cylinder model for predicting concrete crack development and bond strength evolution.

Fig. 2. Bilinear tension softening curve for cohesive cracking in the concrete around the rebar.

Fig. 3. Analytically predicted crack width at concrete cover surface as a function of corrosion level, compared with experimental results for different cover thicknesses.

Fig. 4. Predicted radial corrosion pressure at bond interface as a function of corrosion level, compared with other analytical results.

Fig. 5. Analytically predicted various contributions and ultimate bond strength as a function of corrosion level, compared with the experimental results for specimens without stirrups.

Fig. 6. Analytically predicted ultimate bond strength as a function of corrosion level, compared with the experimental results for specimens with and without steel stirrups.

Fig. 7. Predicted ultimate bond strength as a function of corrosion level, compared with other analytical results and experimental data. 


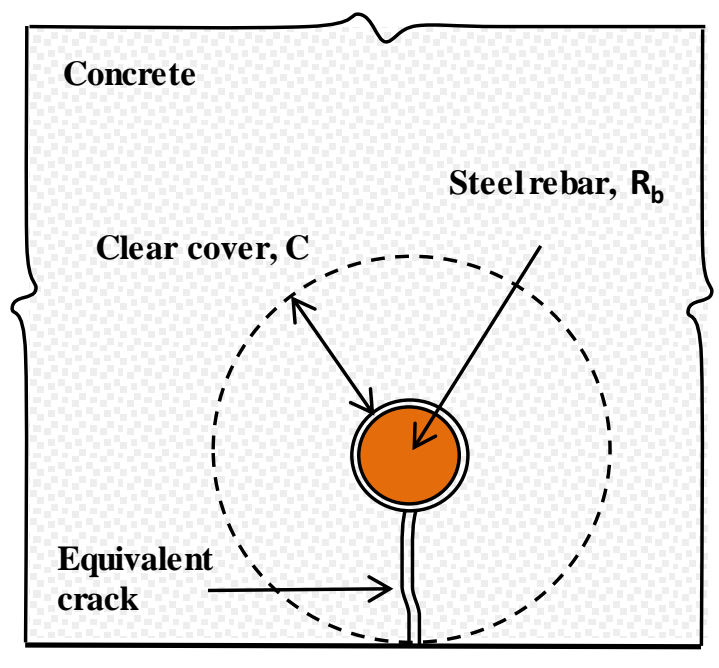

(a) Reinforced bar and the surrounding concrete

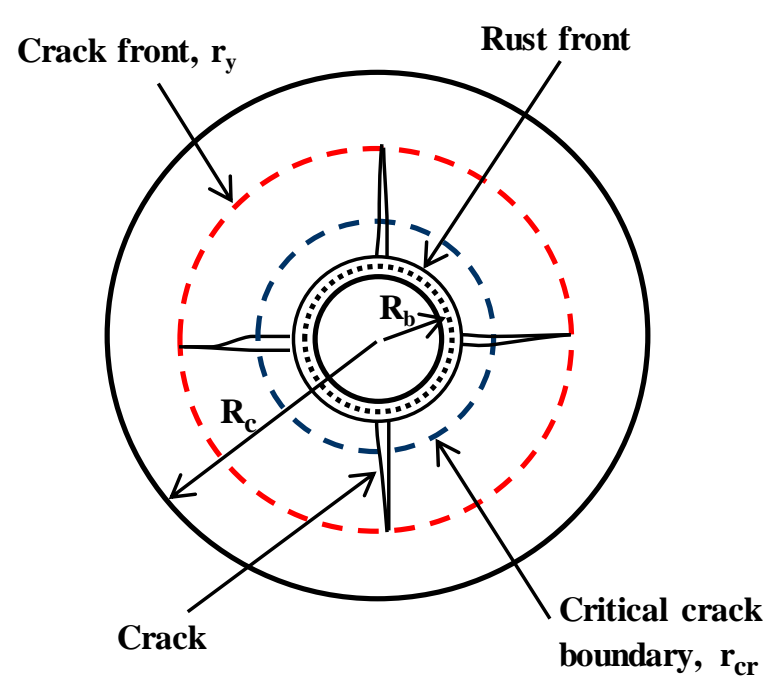

(b) Crack propogation from bond interface to concrete cover surface

Fig. 1. Idealisation of cover concrete as thick-walled cylinder model for predicting concrete crack development and bond strength evolution. 


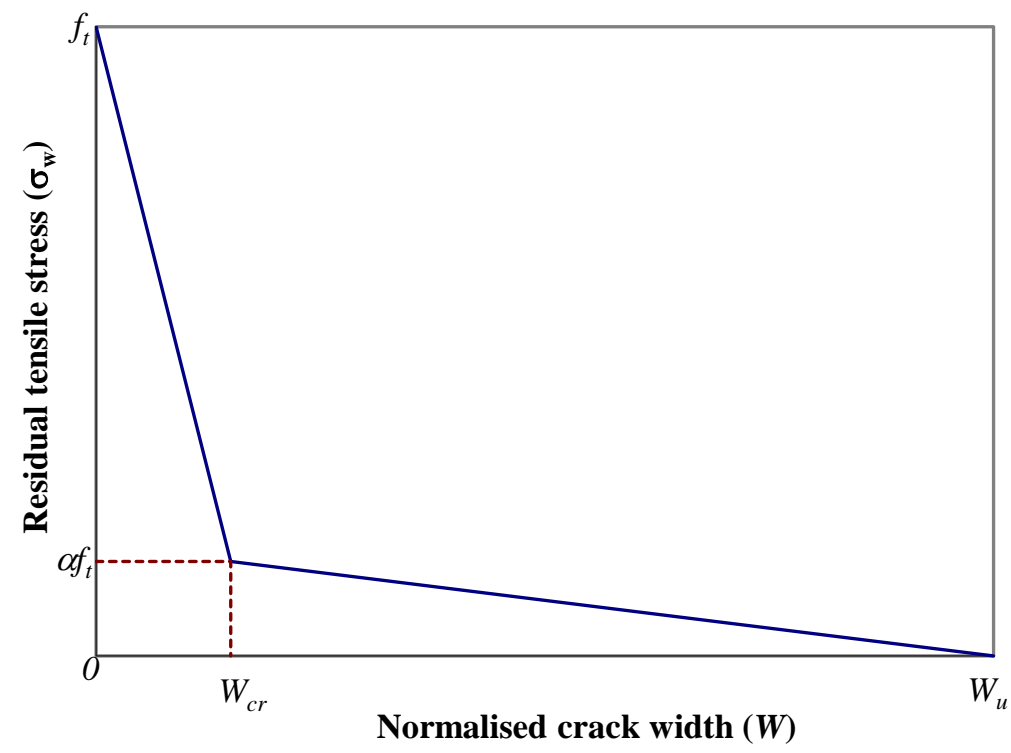

Fig. 2. Bilinear tension softening curve for cohesive cracking in the concrete around the rebar. 


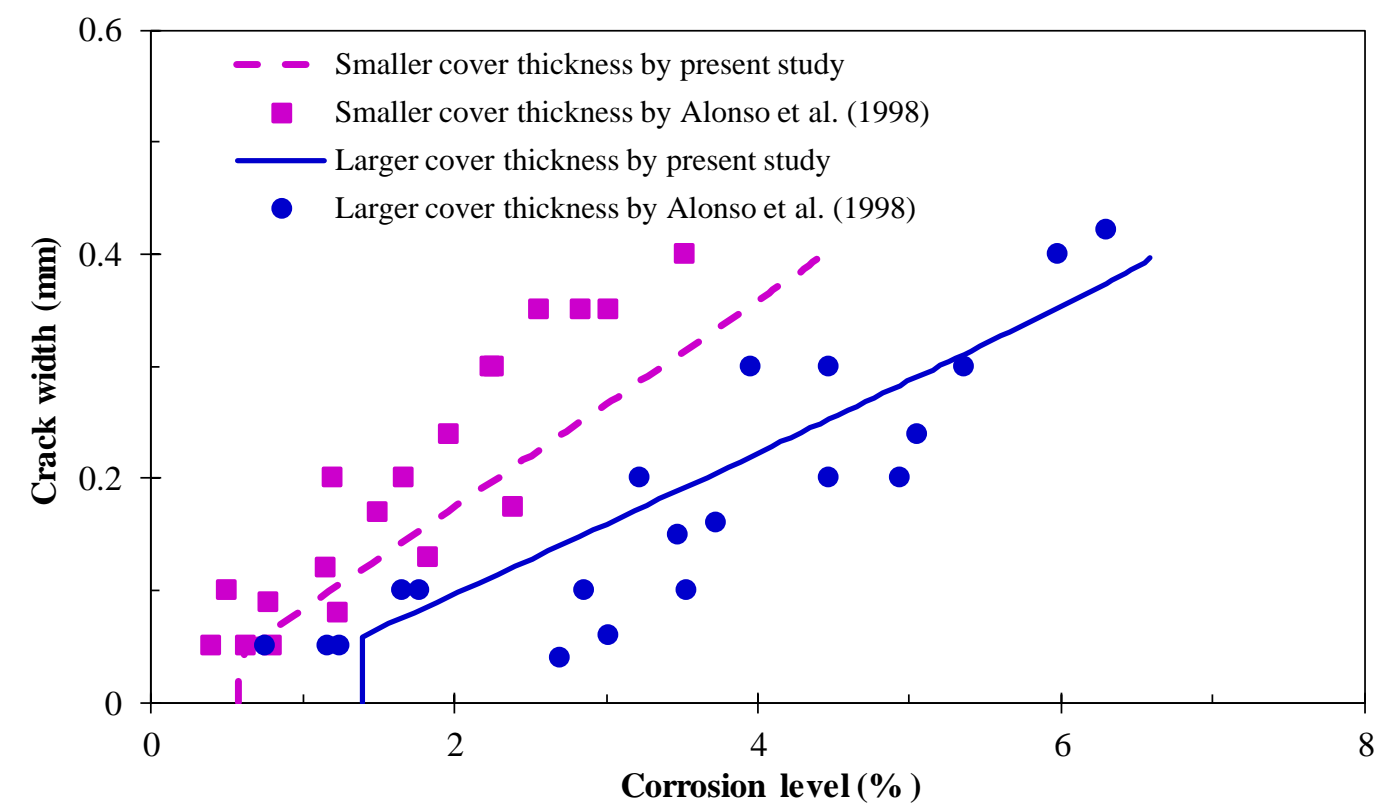

Fig. 3. Analytically predicted crack width at concrete cover surface as a function of corrosion level, compared with experimental results for different cover thicknesses. 


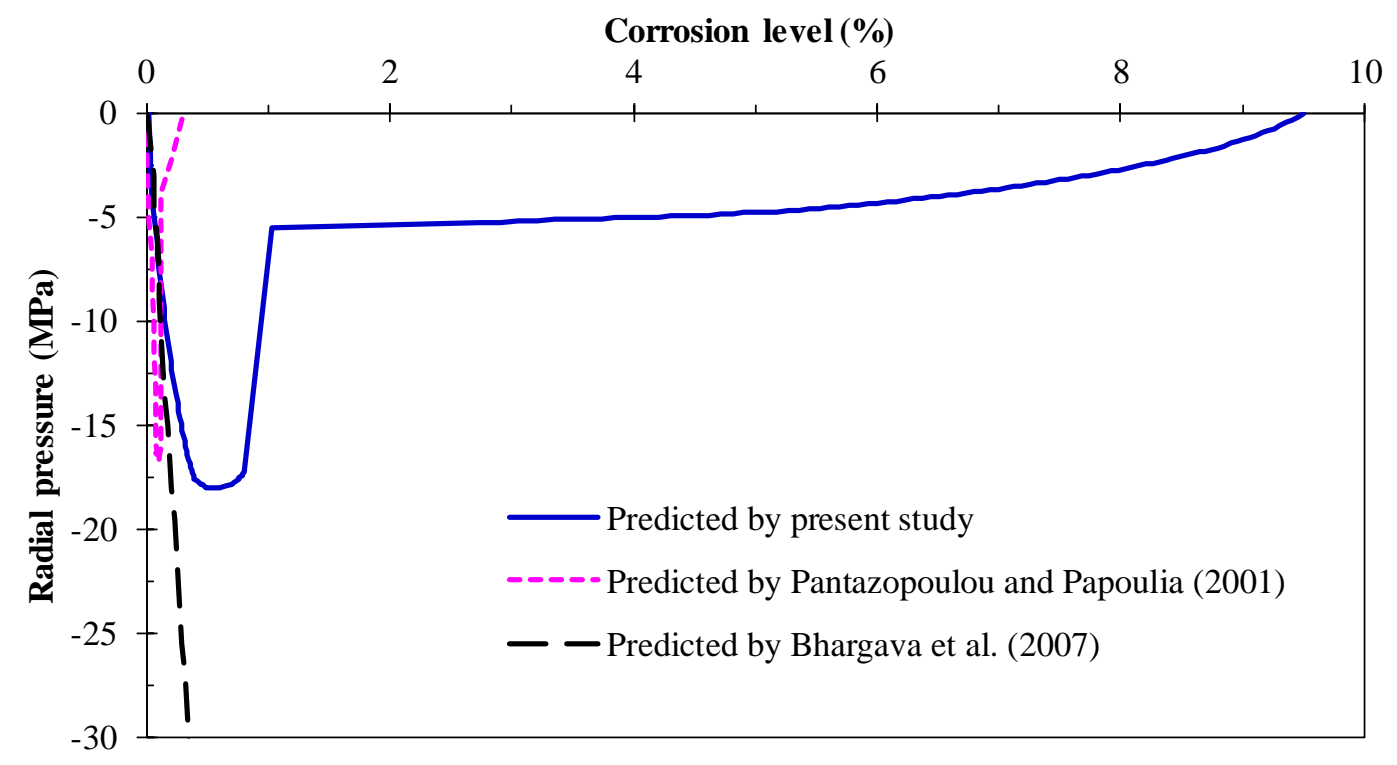

Fig. 4. Predicted radial corrosion pressure at bond interface as a function of corrosion level, compared with other analytical results. 


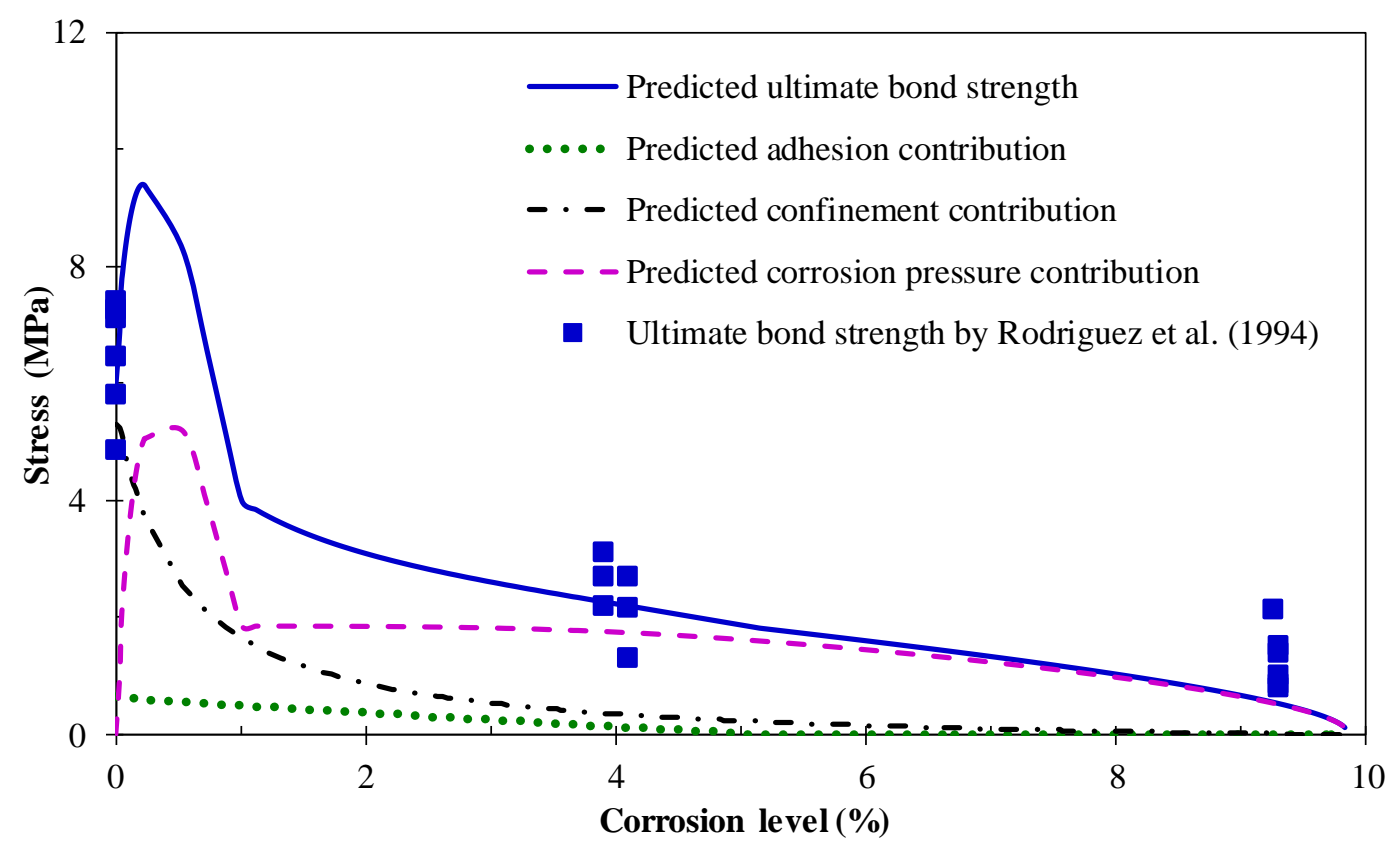

Fig. 5. Analytically predicted various contributions and ultimate bond strength as a function of corrosion level, compared with the experimental results for specimens without stirrups. 


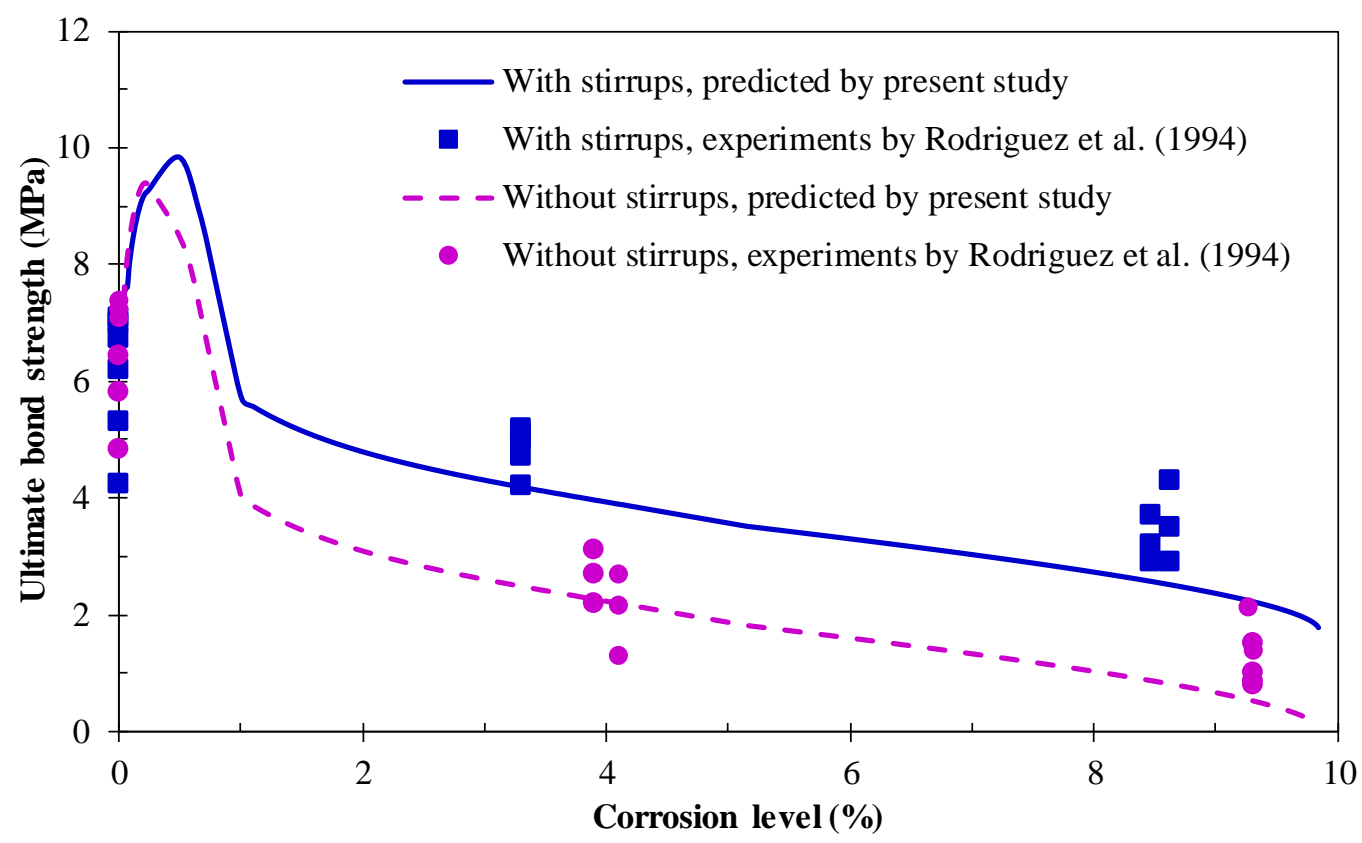

Fig. 6. Analytically predicted ultimate bond strength as a function of corrosion level, compared with the experimental results for specimens with and without steel stirrups. 


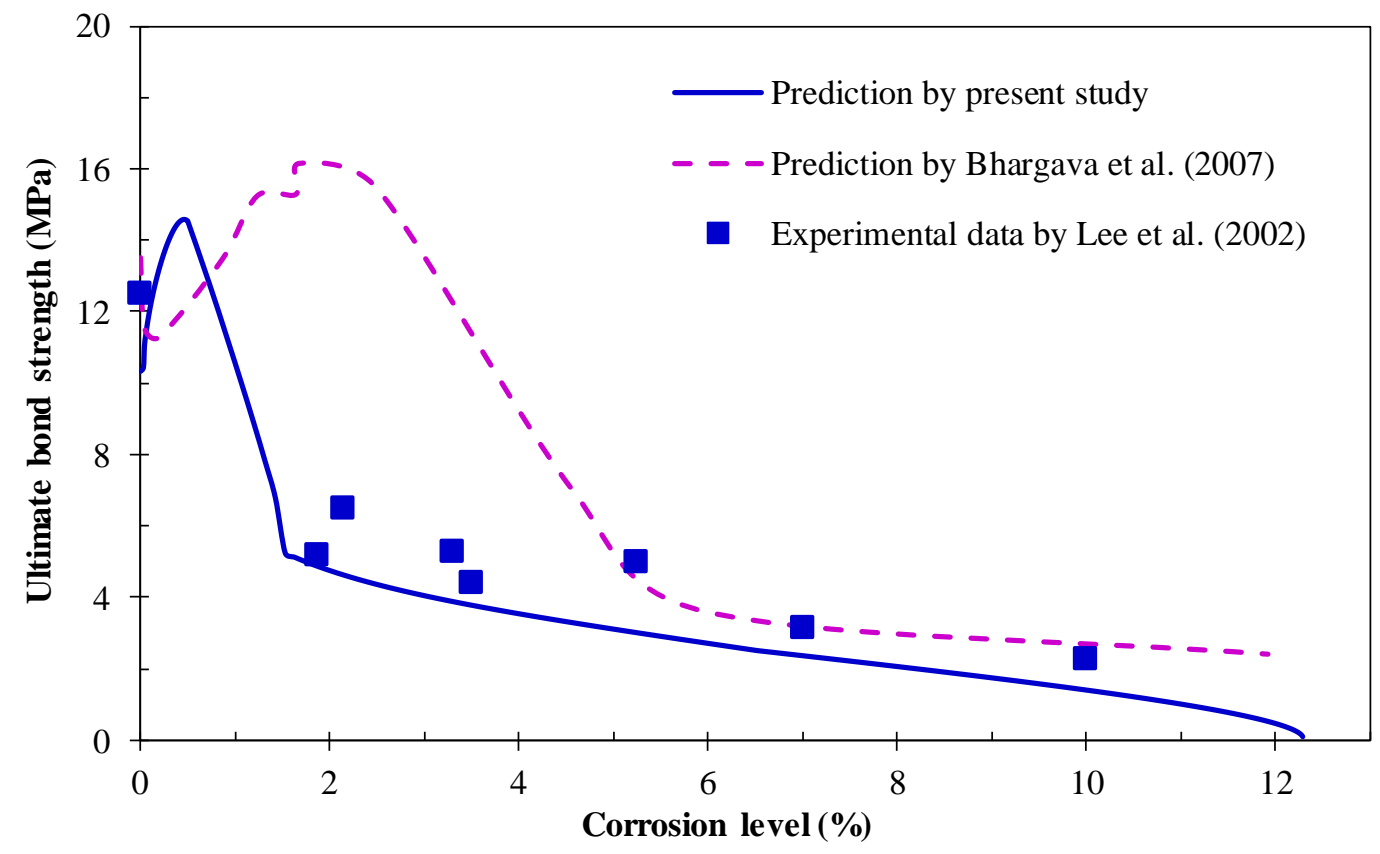

Fig. 7. Predicted ultimate bond strength as a function of corrosion level, compared with other analytical results and experimental data. 